\title{
IV. LOS PROCESOS ELECTORALES EN AMÉRICA CENTRAL (II)
}

HONDURAS: TRANSICIÓN POLITIICA Y PROCESOS ELECTORALES

\author{
CAYETANO NÚÑEZ RIVERO \\ Profesor Titular de Derecho Político \\ UNED
}


SUMARIO

LOS PROCESOS ELECTORALES EN AMÉRICA CENTRAL (II). HONDURAS: TRANSICIÓN POLITICA Y PROCESOS ELECTORALES.-I. EL PROCESO DE TRANSICION POLITICA. - II. EL SISTEMA ELECTORAL.-1. La Jefatura del Estado. 1.1. El Sufragio Pasivo. 1.2. El Sufragio ACtivo. 1.3. La elección del Presidente. 2. El Poder Legislativo. 2.1. El Sufragio Pasivo. 2.2. El Sufragio Activo. III. LA ORGANIZACION ELECTORAL.-IV. LAS FUERZAS POLITICAS.-1. El modelo de Partidos. 2. La financiación de los Partidos Políticos. 2.1. La financiación pública directa. 2.2. La financiación pública indirecta. 2.3. La financiación privada. 3. Los principales Partidos Políticos.-V. RResultados electorales. - Conclusiones. 
Revista de Derecho Político, núm. 33, 1991, pp. 437-473

\title{
IV. LOS PROCESOS ELECTORALES EN AMÉRICA CENTRAL (II)
}

\author{
POR \\ CAYETANO NÚÑEZ RIVERO \\ Profesor Titular de Derecho Político
}

UNED

\section{HONDURAS: TRANSICIÓN POLÍTICA Y PROCESOS ELECTORALES}

\section{EL PROCESO DE TRANSICIÓN POLITICA}

Pocos procesos de transición política, si entendemos como tal el paso de un régimen de carácter autoritario o gobierno no legitimado por las urnas, a otro caracterizado porque el ejercicio del poder se justifica sólo en los principios de la democracia representativa, han sido o son tan largos como en el caso de la República de Honduras. Dentro de la dificultad que implica tener que fijar una fecha de inicio y otra de culminación, podríamos apuntar la del 20 de abril de 1980, celebración de las elecciones que darán lugar a la formación de la Asamblea Nacional Constituyente, y la de enero de 1990, en la que un Presidente de la República, elegido por mandato popular, y tras agotar el periodo previsto por el texto constitucional, hace entrega de la Jefatura del Estado a otro electo y de diferente formación política.

Empero, para saber si se ha ultimado el proceso de transición, es necesario comprobar si los problemas endémicos de la sociedad hondureña han sido resueltos en su mayor parte, o simplemente han quedado enmascarados en un constitucionalismo más nominal que normativo. Entre los problemas principales existentes en dicha sociedad con anterioridad al proceso de restauración democrática podemos señalar los siguientes: control del Aparato del Estado por las Fuerzas Armadas; debilidad de las Organizaciones Políticas, ya que los dos grandes partidos tradicionales no 
pasaban de ser partidos de notables; fuerte dependencia exterior de carácter directo entre la que cabe destacar la presencia militar norteamericana en el territorio; graves problemas de infraestructura en cuanto a aspectos sociales y económicos se refiere; corrupción en la Administración del Estado, etc.

En ciertos aspectos, el proceso de cambio social y político se inicia en Honduras en la década de los setenta, procediendo a institucionalizarse al final de la misma, en la denominada Era Carter. El cuatro de diciembre de 1972, una vez más, un golpe de Estado interrumpe la vida política del pais, derrocando en esta ocasión al Presidente Ramón Ernesto Cruz, que, por otra parte, nunca había podido extender su mandato sobre las Fuerzas Armadas, ya que el control del ejército había sido retenido por el General Oswaldo López Arellano, anterior Jefe del Estado, que protagonizaría la sublevación militar, accediendo de nuevo a la Presidencia de la República.

Esta nueva toma del poder por los militares va a presentar algunas diferencias con respecto a anteriores ocasiones, ya que se presentará como reformista y renovadora, estando fuertemente influenciada por la actitud de otros ejércitos latinoamericanos, fundamentalmente por el peruano de Velasco Alvarado y el panameño de Omar Torrijos, aunque en el caso hondureño con un menor contenido ideológico y nacionalista.

El Régimen Militar contó con el apoyo de amplios sectores de la población, como la Confederación de Trabajadores de Honduras, organizaciones obreras, estudiantiles, etc.; sin embargo, tuvo la oposición de la clase política del país, encabezada por los partidos Nacional y Liberal, así como por sectores empresariales de carácter inmovilista, que propugnaban una vuelta al sistema de "democracia formal» para el país. El Gobierno de López Arellano se caracterizó por la puesta en marcha de una serie de reformas de carácter tímido ${ }^{1}$, aunque absolutamente necesarias. A este respecto, cabe destacar el inicio del Plan de Desarrollo (74-78), la profundización de la Reforma Agraria, y la nacionalización de las riquezas básicas del país, mediante la creación de empresas estatales autónomas, como la Corporación Nacional de Inversiones (CONADI), la Corporación Hondureña del Banano (COHBANA), etc.; por otra parte se aseguró el abastecimiento de productos básicos merced a la política social potenciada por el Banco Nacional de Fomento y otras empresas como BANASUPRO; se estableció el salario mínimo y se posibilitó el desarrollo de las organizaciones sindicales en el campo y la industria. Pero como indica Vinelli ${ }^{2}$ estas reformas de carácter populista desalentaron a la inversión privada, lo que unido a

1 Véase Paul VINELLI: "La Economía hondureña: rasgos generales de su desenvolvimiento", en Honduras, realidad nacional y crisis regional. CEDOH: UNIV. Int. de la Florida. Honduras 1986.

2 Paul Vinelli: op. cit. ant. 
desastres climatológicos produjeron una contracción del 10 por 100 en el sector agropecuario entre los años 1973 y 75.

Durante el periodo citado se puso de manifiesto el enfrentamiento entre dos opciones ${ }^{3}$, una representada por las empresas privadas y los partidos políticos, partidarios de una economía clásica liberal próxima al "Estado Mínimo", con un gobierno que no tuviera carácter intervencionista, y otra postura, de carácter más progresista en los campos económico y social, aunque menos preocupada por el orden constitucional y partidaria de gobiernos intervencionistas, al menos, en estos estadios de subdesarrollo.

La tibieza de las reformas emprendidas por el Régimen Militar hondureño, se diferencia de las llevadas a cabo por el nacionalismo torrijista o el progresismo peruano, que fueron defendidas incluso por sectores de la izquierda, en sus respectivos países, impidieron un mayor arraigo popular del gobierno militar. Por otra parte, la corrupción administrativa reinante en el país llegó a alcanzar a algunos miembros del propio gobierno (sobornos de la United Brands), lo que propició que el veintidós de abril de 1975, López de Arellano hubiera de dimitir, accediendo a la Presidencia el también militar Juan Alberto Melgar Castro.

La caida de López de Arellano significó el fin de la experiencia pseudopopulista en Honduras. El nuevo Presidente partidario de la vuelta al Régimen de Democracia Clásica anunció el retorno a ese sistema político para 1979; en este sentido, promulgó en 1977 una nueva Ley Electoral ${ }^{4}$, que entraría en vigor el primero de enero de 1978; en la nueva ley se contemplaba la existencia de un Tribunal Nacional de Elecciones compuesto fundamentalmente por miembros designados por los partidos políticos. Previamente el General Melgar de Castro, en marzo de 1976, había creado el Consejo Asesor del Jefe del Estado ${ }^{5}$, organismo donde debian estar representadas las fuerzas politicas, sociales y económicas del país, además del propio Gobierno. El deseo del Presidente era que este organismo coordinara los pasos hacia el régimen democrático, y que por otra parte supusiera una cierta legitimación del gobierno militar. El Consejo no fue bien aceptado ni por los partidos políticos tradicionales, que veían en el mismo una cierta forma de perpetuación del régimen militar, ni por amplios sectores del ejército, que consideraba a este organismo como algo que se interponía al control directo del Gobierno por parte del Consejo Superior de las Fuerzas Armadas, verdadero centro del poder en el pais.

3 Véase Mitchell SELIGSON: «La Economía Politica del Desarrollo Agrario en Honduras", en Honduras, realidad nacional y crisis regional. CEDOH: UNIV. Int. de la Florida. Honduras 1986.

4 La Ley Electoral fue promulgada mediante el Decreto 572 del 27-XII-1977.

5 Véase Mario Posas: «El Proceso de democratización en Honduras». Edit.

Estudios Sociales Centroamericanos, . $^{\circ} 47$. San José, 1988. 
En virtud de esta disparidad de criterios entre la Jefatura del Estado y las Fuerzas Armadas, el siete de agosto de 1982, el General Melgar de Castro fue sustituido ${ }^{6}$, pasando el poder a una Junta Militar compuesta por tres generales en la que destacaba la figura de Policarpo Paz Garcia ?

El nuevo gobierno procedió a la disolución del Consejo Asesor del Jefe del Estado ${ }^{8}$, y a la convocatoria de elecciones para la Asamblea Nacional Constituyente, que fueron fijadas por el Tribunal Nacional de Elecciones para el veinte de abril de 1980. c..

Las elecciones habidas, que fueron calificadas por organismos internacionales y observadores extranjeros como las más «limpias» celebradas en el país en muchos años, dieron lugar a un Parlamento de mayoria pára el Partido Liberal (35 escaños), seguido del Partido Nacional (32 escaños) y con tres para el PINV.

En la transparencia de este proceso electoral y en la posterior institucionalización del régimen democrático contribuyeron decisivamente influencias foráneas, derivadas fundamentalmente de la doctrina Carter, que tendía a la necesidad de acabar con dictaduras y gobiernos militares en América Latina, así como a la especial situación de Centroamérica por el peligro de un proceso revolucionario como el habido en Nicaragua, o la situación de guerra civil del Salvador; en este contexto, la política norteamericana lógicamente debía basarse en el apuntalamiento de regimenes democráticos que imposibilitaran levantamientos populares, y en los que el ejercicio del poder estuviera legitimado por las urnas y no por las Fuerzas Armadas. Sin embargo, los mismos factores que posibilitaron el proceso democrático constituian también la mayor amenaza para el mismo, ya que parte del pais estaba controlado por fuerzas extranjeras: la "Contra nicaragüense», oficialmente, y el ejército americano por medio de asesores, prácticamente. Este aspecto justificó que las Fuerzas Armadas de Honduras, aún renunciando al control directo del poder, siguieran conservando parte del mismo, y como indica Posas ${ }^{9}$ «el dominio ejercido por los militares hondureños sobre el conjunto de la sociedad y sobre las instituciones políticas representativas, y el ascendiente que disfruta entre las mismas la denominada doctrina de la seguridad nacional, ha dado como resultado la instauración de un modelo de democracia liberal que un conocido abogado capitolino bautizó como 'deficiente', porque es incapaz de garantizar el respeto a los derechos individuales y sociales establecidos en la Constitución Política vigente».

6 Sobre la caida de Melgar de Castro véase Mario Posas, op. cit. ant.

7 Véase Víctor MEzA: Honduras, la evolución de la crisis. Edit. Universitaria. Tegucigalpa, 1982.

8 El Consejo fue disuelto el 16 de agosto de 1988.

9 Mario Posas, op. cit. ant. 
En cualquier caso, desde las primeras elecciones, se han dado importantes pasos en la consolidación del régimen político de democracia representativa, asi en abril de 1981, el país contó con una nueva Ley Electoral y de las Organizaciones Políticas, que garantizaba el sistema democrático, en cuanto a la inserción de los partidos políticos en la vida política normal de la República, y garantizaba el derecho al voto a la ciudadanía, llevando al poder al primer Presidente civil electo: Suazo Córdova. El 11 de enero de 1982, el país se dotó de un nuevo texto constitucional. Desde ese momento, y hasta el presente, Honduras ha tenido tres Jefes de Estado electos, procediéndose al recambio del poder mediante procesos electorales y sin intervenciones foráneas. El último ha significado, además, el triunfo del partido político opositor, con lo que en muchos aspectos podemos decir que el sistema político está funcionando.

\section{EL SISTEMA ELECTORAL}

En virtud del artículo 167 de la Ley Electoral, las elecciones para la Jefatura del Estado y el Congreso Nacional fueron convocadas para el día 26 de noviembre de 1989. De esta forma se aseguraba que la toma de posesión del Presidente de la República y los tres designados a la Presidencia se llevase a cabo el día 27 de enero del siguiente año, cumpliendo con el rígido procedimiento expuesto en el artículo 237 del texto constitucional. Los parlamentarios constituirían, por su parte, el Congreso Nacional el 21 de enero de 1990, de acuerdo con lo estipulado en los artículos 194 y 197 de la Constitución.

\section{La Jefatura del Estado}

Destaca especialmente la rigidez de la legislación hondureña en cuanto a la improrrogabilidad del mandato del Presidente de la República, así como en lo que respecta al sufragio pasivo.

En el primer aspecto, es de todo punto imposible la prolongación del ejercicio presidencial por más de cuatro años, ya que si la elección del Presidente y designados no estuviese declarada un día antes del 27 de enero, el Poder Ejecutivo ${ }^{10}$ será ejercido excepcionalmente por el Consejo

10 El régimen político hondureño es de un marcado presidencialismo. 
de Ministros, que deberá convocar elecciones dentro de los quince días siguientes a la fecha anteriormente indicada (art. 242 de la Constitución). Las elecciones en este caso se practicarán dentro de un plazo no menor de cuatro ni mayor de seis meses, contados desde la fecha de la convocatoria. Celebradas las elecciones, el Tribunal Nacional de Elecciones, o en su defecto, el Congreso Nacional o la Corte Suprema de Justicia, en su caso, harán la declaratoria correspondiente, dentro de los veinte días siguientes a la fecha de la elección, y los electos tomarán inmediatamente posesión de sus cargos hasta completar el periodo constitucional correspondiente. De esta forma, el mandato presidencial y de los designados puede resultar inferior a cuatro años, ya que las fechas del 27 de enero son improrrogables a efectos del siguiente mandato.

En el proceso electoral que nos ocupa, este fue uno de los puntos de mayor fricción, ya que al observarse que existian ciertas irregularidades en el censo electoral, el presidente del Congreso propuso una vez puesto en marcha el mecanismo electoral que las elecciones sufrieran un retroceso con el fin de poner al día el censo; esta petición que no llegó a ser oficial no pudo ser tramitada en cuanto que cualquier medida tendente a retrasar el día señalado para la celebración de las elecciones es claramente inconstitucional, y que si ello implica una prolongación en el mandato de las personas que detentan el poder ejecutivo, por el artículo 239 del texto constitucional «el que quebrante esta disposición o proponga su reforma... cesará de inmediato en el desempeño de su cargo, y quedará inhabilitado por diez años para el ejercicio de toda función pública», por este artículo aunque podría desprenderse del mismo que afecta sólo al Presidente de la República o Designados, podria entenderse que alcanza a todo funcionario, incluidos desde luego los miembros del Tribunal Nacional de Elecciones y Miembros del Parlamento.

Por otra parte en el Capitulo $\mathrm{V}$ «De la función electoral» del texto constitucional, el artículo 56 pone de manifiesto que cualquier modificación en el Censo Nacional Electoral ha de rechazarse cumpliendo los plazos que determina la Ley, y ésta mediante el artículo 252 (Ley Electoral y de las Organizaciones Políticas), indica que por el Tribunal Nacional de Elecciones deberá terminar obligatoriamente la elaboración del Censo Nacional Electoral por lo menos veinte días antes de la fecha señalada para las elecciones, período dentro del cual, el Tribunal Nacional de Elecciones deberá hacer llegar a los Tribunales Locales de Elecciones, a los Partidos Políticos y Candidaturas Independientes, legalmente inscritas, las listas de electores que correspondan, observando los plazos mínimos que fija dicha Ley. La solución arbitrada para el problema del censo y en virtud de la comprobación de que el acta estaba incompleta fue de dudosa legalidad, aunque no pueda considerarse inmersa en la inconstitucionalidad: se autorizó el voto de los electores, que aunque no figuraran en el registro de los listados de cada mesa, pudieran probar su identidiad mediante su cédula de identificación nacional, y estuviera dispuesto a depositar ésta en dicha mesa, 
con el fin de que posteriormente pudiese comprobarse su pertenencia al Censo Nacional Electoral.

Este tipo de medidas establecidas en la Constitución hondureña de 1982, así como en la legislación electoral correspondiente se explican fundamentalmente por la inestabilidad política habida en el país durante muchos años, en los que los golpes de Estado de carácter militar se han prodigado con harta frecuencia, y cuando no han detentado el poder directamente, la influencia de las Fuerzas Armadas ha sido patente bien imponiendo candidatos adictos a ellas, bien manipulando el proceso electoral, de tal forma, que desde 1956 a 1981 sólo ha habido dos gobiernos civiles, y aún éstos no pudieron concluir su mandato ${ }^{11}$. En este aspecto, de estos últimos comicios cabe destacar que representa casi un hito histórico el hecho de que un Jefe de Estado adscrito a un partido político (el P. Liberal), entregue pacíficamente la banda presidencial a otro candidato de otro partido político, en este caso el Partido Nacional.

\subsection{El Sufragio Pasivo}

Sobre este punto la legislación hondureña tiene unas características que podemos considerar peculiares, pues junto a las limitaciones clásicas de nacionalidad (por nacimiento), edad (veinte años cumplidos), plena posesión de los derechos, pertenencia en activo y en grado de oficial a las Fuerzas Armadas y Cuerpos de Seguridad del Estado, tiene otras de carácter más restrictivo y algunas de carácter único. Mediante el artículo 238 del texto constitucional y artículo 52 del Código Electoral, se pone de manifiesto la incompatibilidad entre el cargo presidencial y el estado eclesiástico, lo que aunque no suele ser normal en los textos constitucionales de democracia clásica tiene un cierto entroncamiento en el Nacionalismo revolucionario decimonónico centroamericano y mexicano. Destaca la no elegibilidad del Presidente de la República por un segundo mandato, tanto si éste fuese consecutivo o no (art. 239 de la Constitución). En esta línea destaca que tampoco los designados a la Presidencia de la República ${ }^{12}$, ni aún los secretarios y subsecretarios de Estado, puedan acceder desde dicho cargo a la Jefatura del Estado si han ostentado los mismos durante los seis meses anteriores a la fecha de elección (art. 240.1). Idéntica limitación tienen, aunque en este caso el hecho sea común a otros textos constitucionales, aunque nunca con un carácter tan amplio, los miembros

"Véase Óscar Fernandez: «Honduras, 26 de noviembre de 1989", en Boletín Electoral Latinoamericano. IIDH-CAPEL. San José de Costa Rica, 1990, pág. 58.

12 El cargo de Designado a la Presidencia de la República se recoge por primera vez en la Constitución de 1957, en lugar del de Vicepresidente que existía en el texto de 1848. 
del Tribunal Nacional de Elecciones, los magistrados y jueces del Poder Judicial, gerentes, subgerentes, directores, subdirectores, presidentes 0 vicepresidentes de las instituciones autónomas o semiautónomas, el contralor y subcontralor general de la República, director y subdirector de Probidad Administrativa (art. 53.a Ley Electoral). Tampoco pueden ser electos los representantes o apoderados de empresas concesionarias del Estado, los concesionarios del Estado para la explotación de riquezas naturales o contratistas de servicios y obras públicas que se costeen con fondos nacionales, y quienes por tales conceptos tengan cuentas pendientes con el Estado (art. 240.7 de la Constitución). Estas incompatibilidades se consideran igualmente dentro de los seis meses anteriores a las elecciones.

De esta forma y mediante la limitación a la financiación de campañas electorales previstas en la Constitución se pretende evitar las posibles presiones de grupos económicos que pudieran influir sobre el ejecutivo. Con referencia a aspectos económicos cabe destacar la curiosa incompatibilidad prevista en el artículo 53.f de la ley anteriormente citada, que indica que no son elegibles «los deudores morosos de la Hacienda Pública», aunque sin indicar a quienes se considera tal, si a aquellos sujetos a sentencia judicial firme, inmersos en un proceso, etc.

Quizás en el punto donde la legislación hondureña tenga un cierto carácter originario es en el referente a las condiciones de elegibilidad aplicadas a los familiares de ciertos cargos públicos, posiblemente el antecedente a este planteamiento sólo puede encontrarse en algunas Repúblicas europeas del siglo XIX que no estando plenamente consolidadas ponían reparos legales a que pudieran acceder a la Jefatura del Estado miembros de la Casa Real anteriormente reinante. Empero el impedimiento hondureño puede derivarse simplemente de su ámbito geopolítico y no de antecedentes decimonónicos europeos, de tal forma, que el ejemplo de dinastías somocistas en Nicargua, duvalieristas en Haití, etc., hayan pesado decisivamente a la hora de redactar el artículo (240.6) del texto constitucional y el 53.d de la Ley Electoral. Mediante estos artículos no son elegibles los parientes del Presidente de la República y Designados a la Presidencia que hayan ejercido la Presidencia en el año precedente a la elección, dentro del cuarto grado de consanguinidad y segundo de afinidad. Este aspecto ha sido varias veces cuestionado por las fuerzas políticas, y en la actual legislatura está previsto su estudio con lo que cabe una posible reforma del texto y ley de desarrollo.

Más radical es si cabe y con menos precedentes históricos, aunque explicable por el particular rol jugado por las FAS en la política hondureña, las trabas que se ponen a los familiares de altos cargos militares, mediante el citado artículo de la Constitución y Ley Electoral que impide la elección de «el cónyuge y los parientes de los jefes militares miembros del Consejo Superior de las Fuerzas Armadas dentro del cuarto grado de consaguinidad y segundo de afinidad". 


\subsection{El Sufragio Activo}

Según el artículo 44 del texto constitucional y el artículo 6 de la Ley Electoral y de las Organizaciones Políticas, en la República de Honduras el sufragio es un derecho y una función pública del ciudadano, quien lo ejerce mediante el voto libre, igualitario, directo y secreto. Es considerado igualmente un deber (art. 40 de la Constitución), y se ejerce desde los dieciocho años (arts. 36 y 37 de la Constitución) ${ }^{13}$, que es la edad que confiere la ciudadanía hondureña. Para ejercitar tal derecho los mayores de dieciocho años deben estar inscritos en el Censo Nacional Electoral, que les proporciona la correspondiente cédula de identificación, dicha inscripción se considera un deber, artículos 144 y 145 ley ant. cit.

Cuatro meses antes de las elecciones, el Registro Nacional de las Personas elabora las listas definitivas de los electores, de tal forma que los Tribunales Locales de Elecciones cuenten con ellos con al menos quince días de antelación a la fecha de elección. En el mismo plazo se remitirán igualmente a los partidos políticos legalmente inscritos (art. 130 Ley ant. cit.). No obstante, lo simplificado del procedimiento expuesto y los controles sobre el censo, este adoleció de bastantes errores que obligan al Tribunal Nacional Electoral a tomar medidas de carácter extraordinario.

Del derecho al sufragio sólo están privados aquellos ciudadanos que por sentencia firme no gocen de sus derechos políticos, o tengan auto de prisión por delito que merezca pena mayor de cinco años: así como aquellos que estén privados de su libertad por sentencia condenatoria firme, dictada por causa de delito y quienes se encuentren prófugos. Tampoco pueden ejercitar dicho derecho los que estén bajo interdicción civil; y quienes sean militares de alta en las Fuerzas Armadas y Cuerpos de Seguridad o de Policía del Estado y Custodios de los Centros Penales.

\subsection{La elección del Presidente}

El Presidente de la República y los tres Designados a la Presidencia son electos conjuntamente y directamente por el pueblo, por simple mayoría de votos ${ }^{14}$.

En el régimen político hondureño se ha alcanzado con la Constitución de 1982 un alto grado de constitucionalización de los partidos políticos, de

13 Sobre la evolución del sufragio en el constitucionalismo hondureño véase Efraín MonCADA SiLva: “Legislación Electoral: Honduras», págs. 182-190, en Legislación Electoral Comparada. Eds. CAPEL. 1986. San José de Costa Rica.

14 Véase artículo 236 de la Constitución y artículo 3 de la Ley Electoral. 
tal forma que se consideran a éstos las formas de organización y participación políticas de los ciudadanos, y en este sentido representantes de los mismos forman parte de los organismos relacionados con todo el proceso electoral. Así mediante el artículo 58 de la Ley Electoral recae sobre los organismos directivos centrales de las organizaciones políticas gestionar ante el Tribunal Nacional de Elecciones la inscripción de los candidatos a Presidente de la República y Designados a la Presidencia.

No obstante, también pueden concurrir a las elecciones candidatos independientes, pero para ello deberán presentar ante el Tribunal Nacional de Elecciones una relación de ciudadanos que represente al menos el 2 por 100 de los electores inscritos en el Estado, lo que representa una importante traba, ya que las firmas de apoyo deben estar autentificadas; en la práctica este procedimiento ha resultado inviable; por el contrario las fuerzas políticas en su organización interna por imperativo de la legislación hondureña al respecto, deben contar con un funcionamiento democrático de tal forma que una determinada tendencia pueda presentar candidatos a la Jefatura del Estado, con lo que al menos se consigue paliar un cierto dirigismo oficialista.

\section{El Poder Legislativo}

El Poder Legislativo radica en el Congreso de Diputados, que son elegidos por sufragio directo (art. 189). El Congreso de Diputados está compuesto en la actualidad de 128 diputados. El número de diputados viene dado por el número de habitantes de cada Departamento, guardando la relación de un diputado por cada 35.000 habitantes o fracción que exceda de quince mil (art. 189 Ley Elect.), para ello se toma como base el último censo oficial de población, debiendo expresarse en la convocatoria de elecciones el número de representantes que serán elegidos por Departamento (art. 192). En aquellos Departamentos que tuvieran una población menor de 35.000 habitantes se elegirá igualmente un diputado propietario y un diputado suplente. Se elegirán además los diputados por cociente nacional electoral de acuerdo a lo indicado en la Ley Electoral.

El sistema electoral para el Congreso de Diputados es de Representación Proporcional por cocientes electorales ${ }^{15}$. El cociente electoral departamental se obtiene dividiendo el total de votos válidos emitidos en el Departamento entre el número de representantes fijos a elegirse en el mismo. Se declaran electos tantos Diputados propietarios y suplentes respectivos, como cocientes electorales haya obtenido la correspondiente lista

15 Véase artículo 46 de la Constitución y 2 de la Ley Electoral. 
de candidatos. Los votos sobrantes de una lista determinada que no hayan conseguido completar el cociente necesario engrosarán el denominado residuo electoral departamental. En el caso de que ninguna de las listas presentadas haya alcanzado el cociente electoral, se distribuiría los escaños comenzando por la lista que haya obtenido mayor residuo electoral, y en orden descendente, hasta completar el número de escaños en liza en ese Departamento, teniendo en cuenta que si se hubieran recorrido todas las listas se procederá de nuevo de idéntica forma para la distribución de los escaños restantes.

La legislación hondureña permitió en las elecciones de 1985 que una misma organización política concurriera con varias listas a una misma elección, en este caso se procederá como en los casos anteriormente indicados, con la diferencia de que el residuo electoral se engrosará a efectos de la última distribución por cociente nacional electoral a su organización política (art. 195). A su vez el cociente nacional electoral se obtiene dividiendo el total de votos válidos depositados en toda la República por el número fijo de representantes que han de elegirse en todo el país. De tal forma, que cada organización política puede obtener tantos diputados por cociente nacional electoral, como cocientes nacionales electorales quepan en la suma de votos sobrantes que el correspondiente partido haya obtenido en todo el Estado, ya que los cargos de Diputados por cociente nacional electoral se adjudicarán a las listas presentadas por las respectivas organizaciones políticas o coaliciones de organizaciones políticas, en los Departamentos que hayan obtenido el mayor número de votos sobrantes ${ }^{16}$, y si fueran varios Diputados por cociente nacional electoral los que deben adjudicarse a una organización política, la adjudicación se hará en orden descendente del número de votos.

\subsection{El Sufragio Pasivo}

Las condiciones para ser Diputado electo son similares a las indicadas anteriormente para la Jefatura del Estado con la variante de la limitación de edad, que en este caso pasa a ser de veintiún años y la obligación de residencia, de al menos cinco años anteriores a la fecha de convocatoria de elecciones, en el Departamento por el cual se postula (art. 198 Constitución). Tampoco pueden ser elegidos como Diputados el Presidente de la República y Designados a la Presidencia, salvo en el caso que optaran por este puesto en lugar de los anteriormente indicados. Siguiendo las pau-

${ }_{16}$ Se entiende por votos sobrantes los que quedan a un partido politico o coalición de partidos políticos, una vez deducidos los votos que hayan sido utilizados para la adjudicación de Diputados por cociente electoral departamental o residuo electoral departamental (Ley Electoral, art. 193). 
tas marcadas para la Jefatura del Estado, tampoco pueden ser electos los altos cargos públicos que desempeñaron dichos puestos dentro de los seis meses anteriores a la fecha de elecciones, tales como secretarios y subsecretarios de Estado, jefes militares en activo, funcionarios públicos excepto los del campo docente y la salud, magistrados y miembros del Tribunal Nacional de Elecciones, así como los familiares en los términos indicados anteriormente con motivo de la Jefatura del Estado; tampoco pueden hacerlo los demás supuestos indicados en el apartado anterior. Empero el Diputado no tiene límite en su capacidad de reelección, y sus familias pueden concurrir igualmente (art. 55 Ley Electoral).

\subsection{El Sufragio Activo}

Las elecciones para el Congreso de Diputados se rigen, en cuanto al sufragio activo se refiere, por las mismas condiciones expresadas anteriormente para las elecciones a la Jefatura del Estado con las salvedades expuestas en el primer epígrafe del presente trabajo sobre el Poder Legislativo.

\section{LA ORGANIZACIÓN ELECTORAL}

Todo lo relacionado con los actos y procedimientos electorales compete al Tribunal Nacional de Elecciones, organismo de carácter autónomo e independiente, con jurisdicción sobre todo el Estado (art. 51 Constitución).

De este organismo dependen los Tribunales Departamentales de Elecciones, los Tribunales Locales de Elecciones y las Mesas Electorales (una por cada 300 electores) (art. 83 Ley Electoral).

Los miembros del Tribunal Electoral son nombrados por el ejecutivo, por medio de la Secretaría de Gobernación y Justicia, comprendiendo:

- Un propietario y un suplente que son designados por la Corte Suprema de Justicia. 
- Un propietario y un suplente designados por cada uno de los partidos políticos legalmente inscritos ${ }^{17}$.

La presidencia del Tribunal es ejercida por un año y en forma rotativa por cada uno de los miembros propietarios que lo integran al igual que los cargos de Vicepresidente y Secretario (art. 53 Constitución). tes:

Las atribuciones del Tribunal Nacional de Elecciones son las siguien-

- Emitir el reglamento interior que regulará el funcionamiento de los órganos electorales.

- Proponer al Poder Ejecutivo el Presupuesto de Gastos de los organismos electorales ${ }^{18}$.

- Inscribir a los partidos políticos y a los candidatos que reúnan los requisitos legales.

- Elaboración del material que exige la práctica de las elecciones.

- Convocar las elecciones, según el calendario previsto en el texto constitucional.

- Cuenta igualmente con iniciativa de ley en asuntos electorales y colabora en la elaboración de proyectos de leyes que interesan al proceso electoral. Asimismo, conoce y resuelve sobre quejas y consultas que le sean sometidas sobre temas electorales.

- Velar porque se respeten y reconozcan a los ciudadanos y a las organizaciones políticas legalmente constituidas, las garantías y derechos que señalan la Constitución de la República, la Ley Electoral y demás legislación en relación a sus actividades políticas y electorales.

17 Por tanto, el número de miembros no ha de ser forzosamente fijo, ya que depende del número de partidos inscritos. La legislación prevé que en caso de ser par el número de miembros, el poder ejecutivo, previa designación de la Corte Suprema de Justicia nombrará de inmediato un miembro adicional con el fin de que el número sea impar (art. 103 Ley Electoral).

18 Se exceptúan los correspondientes al Registro Nacional de Personas que será presentado directamente por ese organismo. 
- Investigar las denuncias presentadas contra las diferentes actividades civiles o militares por violaciones a los derechos electorales y políticos, y si fuesen comprobadas las pone en conocimiento de la autoridad judicial competente.

- Divulgar por todos los medios disponibles el sistema electoral adoptado y publicar por lo menos con treinta días de anticipación a la fecha en que se han de verificar las elecciones, las instrucciones que para la realización de las mismas han de tener las Mesas Electorales.

- Declarar la elección de los candidatos electos y extender las credenciales pertinentes ${ }^{19}$.

- Conocer en única instancia de la nulidad de las elecciones y en su caso fijar la fecha para nuevas elecciones ${ }^{20}$.

- Cuenta con respecto al Censo Nacional Electoral y Registro con las atribuciones de supervisar la elaboración del mismo y nombrar a la dirección correspondiente, así como a los miembros de los Tribunales Departamentales y Locales de Elecciones.

- Convoca y preside las reuniones consultivas de los miembros de los Tribunales Departamentales de Elecciones cuando lo exija la importancia de los asuntos a tratar con respecto al sufragio.

Para el ejercicio de sus funciones el Tribunal Nacional Electoral tiene a su disposición los elementos de los cuerpos de Seguridad y, en su defecto, cualquier otro cuerpo armado o actividad que sean necesarios para garantizar el desarrollo, el orden y la imparcialidad de los procesos electorales. En el mismo sentido el Tribunal Nacional de Elecciones dictará, de

19 En virtud del alto grado de constitucionalización de los partidos políticos en el Régimen Politico Hondureño, el Tribunal Nacional de Elecciones, antes de resolver sobre el resultado de una elección, se reúne con los partidos políticos que postularon candidatos y los representantes de candidatos independientes si los hubiera, con el fin de recabar las informaciones que sean necesarias y oír su opinión para fundamentar mejor la declaratoria de elecciones (art. 110 Ley Electoral).

20 Según el artículo 179 de la Ley Electoral, si por causa de fuerza mayor o caso fortuito se imposibilitase la práctica de una elección o ésta fuera nula en una o varias Mesas Electorales, este hecho no afectará la validez de las elecciones llevadas a cabo en otras Mesas o Departamentos, a menos que dichos votos anulados pudieran decidir el resultado final de la elección. 
acuerdo con la Ley Electoral, todas aquellas medidas que fueran necesarias para el orden, libertad y práctica democrática de las elecciones ${ }^{21}$.

El presidente del Tribunal Nacional Electoral debe informar anualmente al Poder Legislativo sobre sus actividades y las de los organismos electorales bajo su dependencia, dicho informe deberá ser rendido personalmente ante el Congreso Nacional, y con asistencia de la totalidad de los miembros del Tribunal Nacional Electoral.

El rango inferior siguiente está constituido por los Tribunales Departamentales de Elecciones, que son nombrados por el Tribunal Nacional de Elecciones y compuestos por designados de cada uno de los partidos políticos legalmente inscritos ${ }^{22}$.

Las funciones más importantes que cumplen los Tribunales Departamentales son:

- Recibir los expedientes relativos a los escrutinios de elecciones verificados en los diferentes Municipios o Distritos de su Departamento y remitirlos al Tribunal Nacional de Elecciones.

- Conocer y resolver sobre quejas relacionadas con la función electoral contra los miembros de los Tribunales Locales, así como denunciar ante el Tribunal Nacional de Elecciones las irregularidades de que tuviera conocimiento con motivo del proceso electoral.

- Conocerá igualmente sobre los asuntos sometidos a su consideración por los Tribunales Locales de Elecciones y los recursos de apelación interpuestos contra las resoluciones emitidas por los tribunales locales de su jurisdicción.

Los Tribunales Locales de Elecciones, son los organismos electorales encargados de la organización, dirección y supervisión del proceso electoral que tienen como ámbito cada cabecera municipal; como se ha indicado anteriormente tienen una relación de dependencia con respecto a los Tribunales Departamentales y al Tribunal Nacional de Elecciones. y 109.

${ }^{21}$ Véase Ley Electoral y de las Organizaciones Políticas, artículos 103, 108

${ }_{22}$ En caso de que el número de miembros fuese par, se procedería de forma similar a lo expuesto en la nota $n .^{\circ} 17$ del presente trabajo, con la salvedad de lo indicado en el artículo 113 de la Ley ant. cit. 
Sus miembros son nombrados por el Tribunal Nacional de Elecciones a propuesta de la Directiva Central de cada partido político legalmente inscrito, el nombramiento se comunicará por poder del Tribunal Departamental de Elecciones. El Tribunal Local, por tanto, estará compuesto por un miembro propietario y un suplente designado por cada partido político, no pudiendo ser par, ya que en este caso se procederá como en el supuesto visto anteriormente para los Tribunales Departamentales (art. 115 Ley Electoral).

Las funciones más importantes encomendadas a los Tribunales Locales son:

- Difusión de la convocatoria electoral prevista, así como de los lugares de votación.

- Nombramiento de las Mesas Electorales y distribución del material correspondiente para el funcionamiento de éstas.

- Cumplir las instrucciones del Tribunal Nacional de Elecciones y del Tribunal Departamental de Elecciones respectivo, en lo que atañe a la preparación, vigilancia y garantía de la libertad del sufragio en su localidad.

- Recibir las actas de las Mesas Electorales receptoras y practicar el escrutinio de votos del Municipio, levantando el acta respectiva, en presencia de los representantes de los partidos políticos presentes y los observadores acreditados por el Tribunal Nacional de Elecciones.

- Remitir al Tribunal Departamental de Elecciones respectivo, a más tardar el día siguiente de aquél en que se realizó la elección, el acta general de elecciones y los otros documentos electorales, con la seguridad debida, dejando copia certificada del original.

- Informar al Tribunal Nacional de Elecciones y al Tribunal Departamental de Elecciones correspondiente sobre las quejas que se relacionen con el desarrollo del proceso electoral.

- Extender sin demora a los representantes de las organizaciones políticas que lo soliciten, certificaciones del acta de las elecciones de su circunscripción (arts. 116 y 117 Ley Electoral).

El último eslabón de la organización electoral son las Mesas Electorales Receptoras que se organizarán y funcionarán en cada una de las 
cabeceras municipales y en las aldeas que tengan como mínimo cuatrocientos electores. En los demás casos se formarán cada trescientos electores o fracción que pase de cien, haciéndose la distribución de los electores de conformidad a su domicilio (art. 118 Ley Electoral).

Los miembros de las Mesas Electorales Receptoras son nombrados por el Tribunal Local de Elecciones, están compuestas por un miembro propietario y un suplente de cada partido político o candidatura independiente legalmente inscrita. Constan de un presidente, un secretario, un escrutador y vocales correspondientes ${ }^{23}$.

Entre las atribuciones y deberes de los miembros de las Mesas Electorales podemos destacar:

- Reclamar al Tribunal Local de Elecciones las urnas, las correspondientes copias del Censo Nacional Electoral y todo el material que sea necesario para la práctica de la elección.

- Dictar las medidas que el caso requiera para guardar el orden durante la votación y práctica del escrutinio, para ello tendrá a sus órdenes directa la Fuerza Pública ${ }^{24}$.

- Identificación del electorado y salvaguarda del secreto de voto del mismo.

- Levantar actas de constitución de la Mesa, así como de cierre y resultado de la votación, haciendo entrega de ello al Tribunal Local de Elecciones ${ }^{25}$.

Completan la Organización Electoral, el Registro Nacional de las Personas y el Censo Nacional Electoral, dependientes del Tribunal Nacional

23 Para garantizar el principio de alternabilidad en el ejercicio de las responsabilidades electorales, los miembros se organizarán internamente según lo dispuesto en los artículos 91 y 113 de la Ley Electoral.

${ }^{24}$ El transporte, vigilancia, custodia y garantias del proceso electoral será por cuenta y responsabilidad de las Fuerzas Armadas, cubriendo los gastos que se ocasionen dentro de la partida presupuestaria especifica que asigne el Poder Ejecutivo.

${ }^{25}$ Las actas del escrutinio son también firmadas por designados en cada mesa de los partidos políticos, que gozan igualmente de la misma inmunidad que los miembros de los organismos electorales. En el caso de que algún miembro de la mesa no quiera firmar el acta, se hará constar asi en la misma, y mientras no se pruebe lo contrario el acta será válida si recibe la firma de la mayoría de sus miembros (arts. 120 c y 122 h Ley ant. cit.). 
de Elecciones que son los organismos encargados de elaborar el Censo de votantes ${ }^{26}$.

Por último, conviene destacar en este apartado del Sistema Electoral, algunos aspectos dentro de la más pura mecánica electoral, que garantizan el cumplimiento de los artículos 44 y 45 del texto constitucional en cuanto a libertad, igualdad y secreto del voto.

A este respecto, cabe resaltar que la legislación hondureña, siguiendo la tónica de otras centroamericanas, peca de reiterativa y de innecesaria en ocasiones, porque duplica los controles sin que esto, al menos desde un punto de vista de estricto Derecho Electoral, parezca necesario; especialmente si lo comparamos con lo habitual en otros Estados de Democracia clásica y occidental, tal como Estados Unidos, España, Francia o Italia.

De esta forma observamos que la impresión de papeletas no debe ser superior al número de votantes y que ese proceso es no solamente controlado por el Tribunal Nacional de Elecciones, sino también por los partidos políticos, mediante un sistema de actas, destrucción de moldes, etcétera ${ }^{27}$, lo que parece claramente innecesario, pues simplemente valdria con el control de las Mesas Electorales que en cumplimiento de la legislación pueden identificar claramente a cada votante e imposibilitar el doble voto.

En el mismo sentido parece innecesario el sistema de sello y doble firma de los boletos electorales ${ }^{28}$.

Otro tanto parece ocurrir con la tinta indeleble que se aplica a los electores, procedimiento por otra parte cada vez más extendido en Hispanoamérica, pero de escasa necesidad si funciona un Censo Nacional Electoral y un Registro de Personas que imposibilite que un elector pueda votar en más de una ocasión, y para lo cual el control de las Mesas Electorales parece suficiente. A este respecto, parecería conveniente que en caso alguno se perdiera el viejo principio de que la burocracia es válida siempre que no sirva para generar más burocracia.

\section{LAS FUERZAS POLÍTICAS}

\section{El modelo de partidos}

La escena política hondureña ha estado marcada, durante casi todo el siglo XX, por el signo del bipartidismo que ha tenido en el Partido Liberal 
y el Partido Nacional sus representantes. Ambas fuerzas políticas podemos definirlas a grandes rasgos como fuerzas conservadoras. Durante tan largo periodo de tiempo las otras fuerzas políticas que han surgido pueden considerarse en ciertos aspectos escisiones de esas dos grandes tendencias, salvo las de izquierda más o menos radical que, por otra parte, no han conseguido su legalización. Sólo a partir de 1965 surgen otras con ciertas posibilidades de desarrollo y de romper en un futuro el bipartidismo. Son el Partido de Unidad e Innovación Nacional (PINU) y el Partido Demócrata Cristiano de Honduras (PDCH).

Sin embargo, la falta de estabilidad del régimen político, la dependencia económica exterior y como consecuencia de ello política, la carencia de cauces adecuados para el planteamiento de una política opositora de diferente cuño propició el surgimiento de fuerzas extrasistema que a su vez debilitaron la consolidación de un sistema de democracia clásica, de tal forma que como en otros lugares de Centroamérica los factores aglutinantes de la sociedad pasaron del ámbito de los partidos políticos a los poderes de facto, especialmente las Fuerzas Armadas.

Será a partir de los años cincuenta cuando aun sin que se produzca un cambio general en la situación económica y política del país, los partidos tradicionales Nacional y Liberal acometen una renovación para transformarse en cauces de participación política y no sólo en expresión de voluntades más o menos caudillistas.

Es en este contexto cuando, a partir de la constitución de 1957, siguiendo las pautas del moderno constitucionalismo europeo surgido de la Segunda Guerra Mundial, se procederá a constitucionalizar los partidos políticos. Mediante este texto, como indica Moncada Silva ${ }^{29}$, se definiría a los partidos políticos como asociaciones constituidas conforme a la Ley..., para fines electorales y de orientación política, dándoles el carácter de instituciones de derecho público y obligando que el funcionamiento interno de los mismos estuviera ajustado a los principios de la democracia liberal representativa. En el mismo sentido se manifestará la Constitución de 1965.

Tras el proceso de transición política iniciado en 1978, el texto vigente de 1982, recogiendo lo expuesto en los dos textos anteriores, profundiza en esa línea de constitucionalización de los partidos políticos.

En este sentido, el artículo 47 de la Constitución, tras una innecesaria redundancia define a los partidos políticos «legalmente inscritos» ${ }^{30}$ como instituciones de derecho público, y como el medio de lograr la efectiva participación política de los ciudadanos. El desarrollo de este artículo y

${ }^{29}$ Véase Efraín Moncada Silva, op. cit. ant, págs. 212 y ss.

30 Como por otra parte no se reconoce el carácter de partido a aquel que no esté inscrito, no se entiende cuál es el posible sentido que tenga esta formulación. 
siguientes se hace mediante la Ley Electoral y de las Organizaciones Políticas.

La Constitución hondureña en su artículo 37 reconoce el derecho de todo ciudadano a asociarse para constituir partidos políticos.

Empero el Estado ejerce un importante control sobre los partidos políticos, tanto en la fase de formación como con posterioridad a su constitución, que en la práctica restringe altamente este derecho.

En el primer caso los requisitos que deben cumplirse para formalizar la inscripción de un partido político son los siguientes:

1. Acta Notarial en la que se haga constar que al menos cincuenta ciudadanos —se debe indicar nombre y documentación de los recurrentes-, han manifestado tal voluntad (art. 24 Ley Electoral).

2. Presentar ante el Tribunal Nacional Electoral una solicitud de inscripción que adjunte al Acta indicada en el punto anterior la siguiente documentación (art. 25 Ley Electoral).

- Declaración de principios.

- Estatutos.

- Funcionamiento de Democracia Interna.

- Símbolo y emblema del partido.

- Programa de acción política.

- Relación de por lo menos 20.000 electores afiliados al partido político que solicitan la inscripción; esta relación contendrá filiación completa y firma, debiendo estar autenticadas por Notario o Juez cartulario.

- Se exige, igualmente, que al menos en el 50 por 100 de los municipios el partido cuente con directivas de carácter local; este aspecto debe acreditarse ante los Tribunales Locales y Departamentales de Elecciones.

3. Recibida la solicitud de inscripción el Tribunal Nacional Electoral ordenará la publicación de la misma acompañada de la relación 
de afiliados en el diario oficial La Gaceta y en otros dos diarios nacionales de amplia circulación (art. 26 Ley Electoral).

4. Transcurrido el plazo para presentar objeciones, y dentro de los treinta dias siguientes, el Tribunal Nacional de Elecciones resolverá (art. 27 Ley ant. cit.).

Si la inscripción es concedida el Tribunal Nacional de Elecciones ordenará la publicación del registro en el diario oficial La Gaceta en el plazo de los cinco días siguientes (art. 28).

En caso negativo, los promotores del partido político pueden recurrir en Amparo ante la Corte Suprema de Justicia, siendo la sentencia de ésta de carácter inapelable (art. 29).

Del procedimiento anteriormente expuesto se desprende la gran dificultad de poder cumplir con los trámites, pues alcanzar la cifra de veinte mil afiliados en un Estado de las características de Honduras es tarea poco menos que imposible, ya que no se trata como en otras legislaciones de firmas que apoyen la petición, sino de verdaderas afiliaciones, siendo la contradición de ¿cómo un partido puede tener afiliados no existiendo jurídicamente tal partido? La única solución a esta situación seria interpretar que la personalidad jurídica del partido se obtiene, aunque de forma provisional, no con motivo de la publicación en la Gaceta por el Tribunal Nacional Electoral, sino en un periodo anterior que es en el momento que el Notario levanta Acta de la voluntad de cincuenta ciudadanos de constituir el partido político.

En cuanto al control que el Estado tiene sobre el funcionamiento de un partido político ya constituido, cabe destacar el ejercido por el Tribunal Nacional de Elecciones con motivo del cumplimiento del principio de democracia interna y el respeto al pluralismo en el seno de la organización política.

En primer lugar cabe destacar que el cumplimiento del artículo $36.3^{31}$ del texto constitucional, tiene un desarrollo tan lineal en la Ley de las Organizaciones Políticas, que en su artículo 17 manifiesta que utodo ciudadano tiene derecho a afiliarse al partido político de su elección", lo que implica que la organización política no puede negarse al ingreso de determinada persona en su formación, pues de hacerlo cuestionaría un derecho de rango constitucional, y ello sin entrar en consideraciones de carácter ideológico o de otro tipo, ya que en el artículo 16 de la citada Ley

31 Son derechos del ciudadano... asociarse para construir partidos políticos, ingresar o renunciar a ellos. 
la afirmación es más rotunda si cabe «la afiliación a los partidos políticos debe mantenerse abierta sin discriminación de clase, sexo, raza o credo". Con ello se pueden producir resultados tan paradójicos como que un partido político puede no llegar a controlar en unas elecciones estatales el voto de sus afiliados, ya que en punto alguno queda excluido, por ejemplo, la doble militancia; es difícil encontrar antecedentes similares en otras legislaciones, sólo y muy parcialmente podemos observar la práctica en algunos Estados norteamericanos en los que puede votarse por personas no afiliadas a un partido político, y en un primer proceso de selección a candidatos que ese partido puede presentar a una confrontación electoral.

Este aspecto es especialmente importante en una legislación como la hondureña que permite y potencia la formación de «tendencias» 0 «movimientos" internos en el seno de los partidos, a los que debe respetarse el principio de representación proporcional (art. 19 Ley ant. cit.), tendencias que en 1985 pudieron concurrir posteriormente en las elecciones presidenciales, legislativas y municipales en listas separadas, compitiendo con otras del mismo partido, aunque al final se sumen los votos obtenidos por todas las listas de una misma fuerza política.

El control del Tribunal Nacional de Elecciones se lleva a cabo con respecto al principio de democracia interna en cada partido mediante la creación de la Comisión Nacional Electoral, compuesta en cada partido por una representación igualitaria de todos los movimientos, corrientes o tendencia internas que participarán en la elección, el Tribunal Nacional de Elecciones más los representantes del Organismo de Dirección Central del partido que sean necesarios para que el número de miembros de la Comisión sea impar. Para la práctica de las elecciones internas, la Comisión Nacional Electoral del respectivo partido político comunicará al Tribunal Nacional de Elecciones quien hará la convocatoria correspondiente con treinta días de anticipación como mínimo a la fecha en que habrán de realizarse dichas elecciones, siendo las mismas supervisadas por el Tribunal Nacional de Elecciones. Por otra parte, es el Tribunal Nacional de Elecciones el que resolverá los recursos planteados contra la resolución de la Comisión Nacional Electoral, debiendo resolver en un plazo no mayor de quince días, vencido el cual, se podra recurrir en amparo ante la Corte Suprema de Justicia, que resolverá dentro del término de treinta días a partir de la fecha de la demanda.

Este tipo de elecciones son obligatorias en todos los partidos políticos y se harán dentro de un plazo de seis meses antes de la convocatoria a elecciones generales, siendo siempre convocadas por el Tribunal Nacional de Elecciones.

De lo expuesto anteriormente tanto en lo que respecta a la formación, inscripción, registro, etc. como al funcionamiento y constitución de los partidos políticos se desprende que el régimen político descansa sobre la base de la estabilidad de grandes formaciones políticas y no de partidos mino- 
ritarios, optando por tanto, aunque sui generis, por el modelo norteamericano y el bipartidismo; de hecho sólo dos formaciones han conseguido irrumpir en el modelo bipartidista impuesto por el Partido Liberal y el Partido Nacional; será por tanto el desarrollo del PINU y el Partido Demócrata Cristiano, todavia hoy formaciones claramente minoritarias, lo que nos indique si el actual sistema de partidos se consolidará en el bipartidismo, o por el contrario esto sólo ha sido el camino para llevar a cabo la transición política, pero el futuro transcurrirá por los cauces del pluripartidismo como expresión del pluralismo político e ideológico fuera de los estrechos márgenes de la situación actual.

\section{La financiación de los Partidos Políticos}

El sistema de financiación previsto en la legislación hondureña para los partidos políticos es de carácter mixto; no obstante, se establecen claras restricciones a las de carácter privado, decantándose en un terreno práctico por las de carácter público.

En nuestra opinión, este hecho se basa en tres supuestos:

a) El alto grado de institucionalización dentro del Régimen Político de los partidos.

b) El bipartidismo imperante casi excluyente.

c) La reciente transición desde un régimen de carácter autoritario a uno de Democracia Clásica.

Aunque la mayoria de los textos constitucionales surgidos con posterioridad a la Segunda Guerra Mundial han procedido a constitucionalizar los partidos políticos, no es frecuente encontrar una manifestación tan rotunda como la contenida en el artículo 47 del texto hondureño que define a los partidos políticos como instituciones de derecho público y como casi única vía de efectiva participación política de los ciudadanos. A este respecto, en el Derecho Constitucional Comparado sólo cabría remontarse a la Ley Fundamental de Bonn y a la constitución Portuguesa de 1976.

En este sentido y si aceptamos el hecho de que los partidos políticos se constituyen en «órganos del Estado» podríamos coincidir con la expre- 
sión de GARCIA COTARELO ${ }^{32}$ de que «no es exagerado decir que, en estos casos, la financiación pủblica es algo que deberia darse por supuesto, pues carece de sentido hablar de los órganos del Estado que se financian con fondos privados".

Indudablemente la financiación pública de los partidos, especialmente la de carácter directo, se encuentra hoy día firmemente implantada, a excepción, quizás, de los países anglosajones, en la mayor parte de las Democracias clásicas. En un primer análisis ello podría suponer un mayor control del aparato del Estado sobre las fuerzas políticas, sin embargo en la práctica estamos asistiendo a un proceso inverso, que seria un incremento del control del Estado por los partidos políticos, hecho éste que ha motivado a numerosos constitucionalistas a aventurar que estamos asistiendo al paso de un Estado Social de Derecho a un Estado Social de partidos ${ }^{33}$, afirmación que puede verse corroborada por el hecho de que los nuevos textos surgidos en el último decenio se decantan como participación política casi exclusivamente por los partidos, caso hondureño, relegando otras formas de participación como las instituciones de democracia directa a niveles muy secundarios o casi inexistentes en virtud de las trabas para su puesta en marcha, exceptuando quizás la culminación de los procesos constituyentes.

Como ya se indicó en apartados anteriores de este trabajo, la vida formalmente democrática habida en Honduras estuvo protagonizada por dos grandes formaciones políticas, que fueron las que por otra parte, junto a las Fuerzas Armadas protagonizaron el proceso constituyente. Es por ello, por lo que no es aventurado sostener que tanto al redactar el texto constitucional como la Ley Electoral y de las Organizaciones Políticas ${ }^{34}$ tuvieran en mente la conformación de un sistema bipartidista que aportara estabilidad al régimen político. En este contexto, es fácil comprobar la amplia financiación pública reservada a las formaciones políticas, ya que el sistema no se basa en la posibilidad de múltiples organizaciones políticas, aunque a cada cambio se manifieste una gran intervención del aparato del Estado en la organización y desarrollo de los dos partidos: aspecto éste, por otra parte, ampliamente compensado en virtud de las grandes atribuciones que los dos partidos tienen en cuanto a composición de distintos órganos del Estado, como el Tribunal Nacional de Elecciones, Tribunales Departamentales, Locales, etc., con lo que el proceso en cierta medida queda invertido como manifestamos anteriormente.

32 Ramón Garcia Cotarelo. Los partidos politicos. Ed. Sistema. Madrid 1985. pág. 217.

33 Ver Antonio Torres del Moral. «El Estado Español de Partidos» Rev. del Centro de Estudios Constitucionales. Madrid 1981.

${ }^{34}$ Véase Títulos I y III de la citada Ley. 
Por último, es destacable que al igual que en el caso de Honduras en la mayor parte de las Democracias clásicas surgidas con posterioridad a regímenes autoritarios, la financiación pública de los partidos políticos ha sido especialmente importante, baste recordar a este respecto los ejemplos de la República Federal Alemana tras la caída del régimen nazi o más recientemente, la España post-franquista. Ello. se debe indudablemente a la idea de que para consolidar el régimen político se considera que es pieza imprescindible consolidar igualmente el sistema de partidos, y que lógicamente éstos, una vez salidos del túnel que supone un largo período dictatorial, aparecen en los nuevos regímenes carentes de fuerza, necesitando medios económicos para su fortalecimiento y reorganización.

\subsection{La financiación pública directa}

El artículo 40 de la Constitución hondureña establece que el Estado contribuirá a financiar los gastos de los partidos políticos, de conformidad con la ley. A este respecto, la Ley Electoral y de las Organizaciones Políticas crea la figura de «deuda política» ${ }^{35}$, que se justifica como el medio de garantizar la independencia de los partidos políticos. Sin embargo, a diferencia de otras legislaciones foráneas no se establecen más que el requisito de concurrir a las elecciones, sin entrar en la necesidad de obtención de escaño o al menos un número determinado de votos para poder acceder a la financiación enunciada.

Es por tanto, en virtud de los sufragios válidos obtenidos como se obtendrá la financiación otorgada por el Gobierno de la República.

La financiación a los partidos politicos se hace previamente a la elección, ajustándose conforme al número de votos obtenidos por el partido en la última elección, aunque no puede ser superior al sesenta por ciento de la cuota que corresponda a cada partido político en dicha elección.

Con el fin de garantizar el principio de igualdad de oportunidades para todos los partidos políticos, el artículo 246 establece que en caso alguno un partido político podrá recibir menos del 15 por 100 de la suma asignada al partido que obtenga el mayor número de sufragios, salvo que dicho partido haya obtenido menos de 25.000 sufragios.

El ajuste final se hará mediante el abono de la Tesorería General de la República de seis lempiras por cada voto válido que haya obtenido un partido en los comicios. 


\subsection{La financiación pública indirecta}

Sobre este punto cabe destacar que las organizaciones políticas gozan de franquicia postal, telegráfica y telefónica, asi como de cualquier otro medio de comunicación oficial, dentro del territorio Nacional, siendo dicha franquicia regulada por el Tribunal Nacional de Elecciones (art. 23 Ley ant. cit.).

En el mismo sentido, los bienes inmuebles que constituyan el patrimonio de las organizaciones políticas están exentos de impuestos y contribuciones locales y municipales (art. 36).

Con respecto a la propaganda política, los partidos pueden introducir al país cada cuatro años, libres de toda clase de impuestos, tasas y derechos, material fotográfico, vehículos automotores y equipos de sonido sin que dichas importaciones excedan la suma de doscientos cincuenta mil lempiras.

Como contrapartida a la financiación pública de los partidos políticos, el Estado ejerce un control que intenta ser bastante rígido con respecto a la fiscalización de ingresos y gastos ${ }^{36}$.

De esta forma los partidos políticos están obligados a llevar contabilidad detallada de todo ingreso o salida de fondos, en la que se indique fecha de los mismos, así como nombre y domicilio de las personas implicadas en ello; esta documentación tendrá que ser conservada durante cinco ejercicios fiscales.

En cada ejercicio anual y en el plazo de noventa días siguientes a su finalización, cada partido deberá presentar ante el Tribunal Nacional de Elecciones un estado de su patrimonio, certificado por contador colegiado. Deberá cumplir igualmente dicho trámite dentro de los noventa días siguientes a las elecciones generales celebradas.

\subsection{La financiación privada}

La financiación de carácter privado a las organizaciones políticas hondureñas tiene un cierto carácter restrictivo, en cuanto que sólo admite aquellas provenientes de cuotas de militantes, contribuciones, herencias, legados, etc., debidamente identificados (art. 33 Ley cit.), negando la posibilidad de recibir de forma directa o indirecta donaciones de carácter anónimo, salvo las obtenidas en colectas populares (art. 34). 
Tampoco puede recibir contribuciones de empresas que tengan concesiones o contratos con el Estado, o de aquellas que exploten juegos de azar y las que directa o indirectamente sean controladas por éstas.

En caso alguno pueden las organizaciones políticas recibir contribuciones o donaciones de personas naturales o juridicas extranjeras, cualquier sea la firma con que éstas actúen, ya sea con personas de derecho público o derecho privado.

El tema del anonimato en las donaciones privadas, que prohibe tan claramente la legislación hondureña, sigue siendo todavía sujeto a debate en la mayor parte de los regímenes políticos de la Democracia occidental, y como indica Pilar DEL CASTILLO ${ }^{37}$, "desde una perspectiva constitucional no es, sin duda, tarea sencilla justificar que la identidad de los donantes deba ser pública. No en vano su constitucionalidad ha sido ampliamente discutida en algunos países, llegándose a adoptar posiciones diametralmente opuestas sobre este problema... El carácter secreto del voto y la posible disminución del número de contribuyentes, si el anonimato no quedaba garantizado, han constituido las normas más comunmente esgrimidos en su contra». No obstante, la tendencia que se observa en la mayoría de los Estados es de que las donaciones sean conocidas, en el caso hondureño, país de reciente restauración democrática, se ha querido evitar que pudiera ocurrir, como ha sido tendencia en épocas anteriores, que las organizaciones políticas fueran dependientes económicamente de familias y compañias nacionales o extranjeras que han marcado la vida política del pais; con el actual sistema se evita que las subvenciones de este tipo sean abultadas, aunque de todas formas no se ha puesto límite de cantidad a las subvenciones privadas conocidas. En todo caso, el sistema aplicado de prohibición del anonimato puede contribuir como indica Pilar DEL CASTILLO ${ }^{38}$ a que los ciudadanos fortalezcan su confianza en el sistema democrático y sea "más transparente el tradicionalmente oscuro y sospechoso mundo... de la financiación política».

Otro análisis quizás pueda merecernos el referente a la prohibición de que los partidos políticos puedan recibir subvenciones o subsidios de gobiernos, organizaciones o instituciones extranjeros, según lo dispuesto en el artículo 50 de la Constitución, pues destacado el primer punto del citado artículo, que parece destinado por el legislador para impedir la creación de partidos de carácter revolucionario. Por el contrario, no parece tener gran sentido que no pueda recibirse ayuda de fuerzas políticas ideológicamente afines en un momento en el que el mundo y especialmente

${ }^{37}$ Pilar del CASTILlo: La financiación de partidos y candidatos en las democracias occidentales. Centro de Investigaciones Sociológicas. Madrid 1985. Ver igualmente «Financiación de las Elecciones Generales de 1986». Revista de Derecho Político, n. ${ }^{\circ}$ 25, pág. 132, Madrid 1987.

${ }^{38}$ Pilar del CAstillo: op. cit. ant., pág. 133. 
América Central parece asistir a un proceso de integración estatal, y aún continental, aspectos éstos que, por otra parte, recogen los textos de los diversos Estados centroamericanos. En nuestra opinión, el mantenimiento de este precepto constitucional, contenido ya en los textos de 1957 y 1965 , es consecuencia de los problemas que históricamente ha mantenido Honduras con sus vecinos y a la especial situación derivada del hecho de mantener Fuerzas Armadas foráneas en su territorio. En todo caso, este aspecto no es más que una manifestación más de la necesidad de consolidación de un sistema que todavía atraviesa graves problemas en cuanto a estabilidad se refiere.

\section{Los principales partidos políticos}

\section{Partido Liberal Hondureño}

Es la formación política más antigua del país, fue fundado en 1891 por Policarpo Bonilla y durante este tiempo ha sufrido numerosas escisiones ${ }^{39}$ que han dado lugar al nacimiento de otros partidos políticos, entre ellos el Partido Liberal. Históricamente ha estado considerado como un partido de carácter progresista, plasmándose dicha tendencia en varios textos constitucionales, hoy dia su política puede calificarse de conservadora. Junto al otro partido indicado anteriormente ha protagonizado íntegramente la vida política hondureña durante más de ochenta años. Desde la transición política de 1982 ha gobernado el país hasta las elecciones de 1989, aunque ha debido soportar numerosas tendencias dentro de su seno ${ }^{40}$, consecuencia de una política "caudillista» de sus principales líderes y quizás de la dificultad de crear otras formaciones políticas lo que ha llevado a que casi exista mayor competencia interna en los mismos partidos que entre los diferentes partidos en Honduras ${ }^{41}$. Como consecuencia de este aspecto ha influido poderosamente en el reconocimiento constitucional de la existencia y protección dentro del texto constitucional de las tendencias y movimientos de los partidos políticos.

Las fracciones más importantes surgidas últimamente en la formación política ha sido la RODISTA (Movimiento Liberal Rodista) y la Alianza

39 Véase Efrain Moncada Silva, op. cit. ant., pág. 211.

40 Véase Ernesto PAZ Agullera: «Sistema Electoral y Representación Política en Honduras", en Sistemas Electorales y Representación Politica en Latinoamérica, Ed. Fund. Ebert., Madrid 1986.

41 Véase Mark Rosemberg: «Democracia en Centroamérica», Eds. Capel, número 5, pág. 27. San José de Costa Rica 1985. 
Liberal del Pueblo (ALIPO), que a su vez se ha dividido en varias corrientes, que abarca desde la derecha pura hasta posturas de centro izquierda. Otros grupos de presión tienen cierto peso en el partido, destacando algunos de carácter empresarial e incluso centrales obreras, aunque destaca especialmente, al igual que en la otra gran fuerza política; el peso de las Fuerzas Armadas ${ }^{42}$.

\section{Partido Nacional}

Nacido en 1902, es el otro gran partido tradicional hondureño, que ha conformado el carácter bipartidista del sistema. De ideología conservadora, ha sido por largo período el partido más representativo de la derecha.

De carácter caudillista durante mucho tiempo, ha estado muy influenciado por las Fuerzas Armadas. Habiendo perdido las dos anteriores confrontaciones electorales, sufrió numerosas divisiones en su seno hasta que el actual presidente Rafael Leonardo Calleja impuso su liderazgo procediendo a una modernización del partido.

Durante la pasada campaña electoral el partido supo hacer una efectiva propaganda entre sectores de nuevos votantes así como en cuanto a información del programa y documentación electoral ${ }^{43}$. Por otra parte organizó una red bien estructurada en cuanto a control de votantes, de afiliados y simpatizantes del partido. En todo caso fue bastante definitiva la imagen de cohesión interna presentada ante los electores.

Partido de Unidad e Innovación Nacional (PINU)

Partido de reciente creación (1978), fuerza de carácter minoritario, intenta incidir en las clases medias, aunque no ha conseguido calar en el electorado, ya que sus resultados en los últimos comicios han sido similares (2.000 votos menos) a los obtenidos en 1980 , y poco más que los alcanzados en 1985.

42 Una de las intervenciones más claras de las Fuerzas Armadas fue el Acta de Compromiso de la Fuerza Aérea Hondureña del 20 de mayo de 1985, que, suscrita por todos los partidos políticos y sindicatos obreros y campesinos, sentó las bases de consolidación del sistema político imperante.

43 Véase Óscar FERNÁNDEZ: «Elecciones Generales en Honduras», en Boletín Electoral Latinoamericano, Capel, San José 1990. 
En las últimas elecciones obtuvo dos diputados, to que representa menos del 2 por 100 del electorado. En la actualidad pertenece a la Internacional Social Demócrata, aunque anteriormente pasó por un largo período de indefinición ideológica.

\section{Partido Demócrata Cristiano (PDCH)}

Nacido en 1981 y de inspiración socialcristiana, aunque ha manifestado ciertas tendencias de centro izquierda. El espacio político en que intenta moverse es el de las clases medias y sectores profesionales.

Es un partido de cuadros que aglutina a ciertos sectores renovadores de la sociedad. No ha conseguido escaño alguno en las pasadas elecciones, e incluso ha bajado casi un 20 por 100 con respecto a los comicios de 1985.

\section{RESULTADOS ELECTORALES}

\section{CUERPO ELECTORAL}

Electores inscritos

Votos emitidos

1.799 .146

Votos válidos

1.753 .556

Votos nulos

18.483

Votos en blanco

27.107 
2. DESGLOSE POR FUERZAS POLITICAS

\begin{tabular}{|c|c|c|}
\hline & NÚM. DE VOTOS & $\begin{array}{l}\% \text { VOTOS } \\
\text { EMITIDOS }\end{array}$ \\
\hline 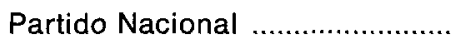 & 917.168 & 50,97 \\
\hline Partido Liberal ............................. & 776.983 & 43,18 \\
\hline Partido de Innovación Nacional. & 33.952 & 1,88 \\
\hline Partido Demócrata Cristiano .... & 25.453 & 1,41 \\
\hline
\end{tabular}

\section{PARLAMENTO}

Diputados nacionalistas

Diputados liberales

Diputados PINU

Diputados PDCH

TOTAL

\begin{tabular}{|c|c|}
\hline NÜM. ESCAÑOS & $\%$ \\
\hline 71 & 55,5 \\
55 & 43 \\
2 & 1,5 \\
0 & 0 \\
\hline 128 & 100 \\
\hline
\end{tabular}




\title{
HONDURAS
}

\section{DESGLOSE POR FUERZAS POLITICAS}

\author{
AÑO 1989
}

(VOTOS VÁLIDOS)

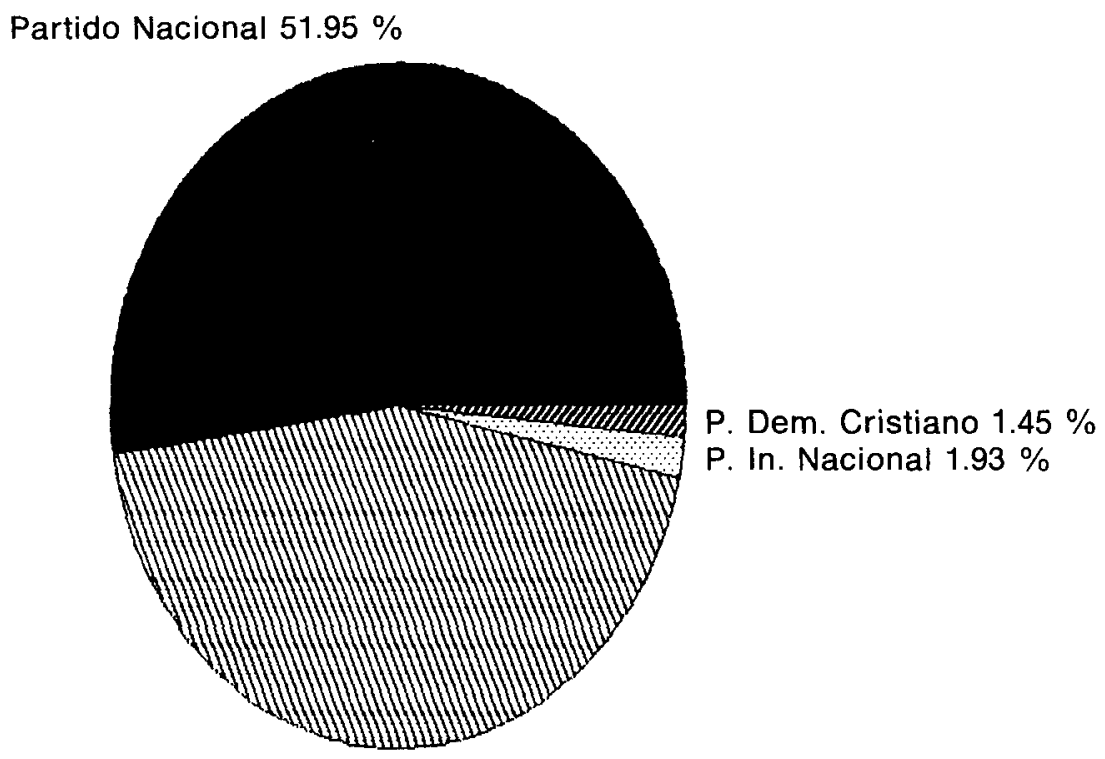

Partido Liberal $44.3 \%$ 
HONDURAS

DISTRIBUCIÓN DE DIPUTADOS

AÑO 1989

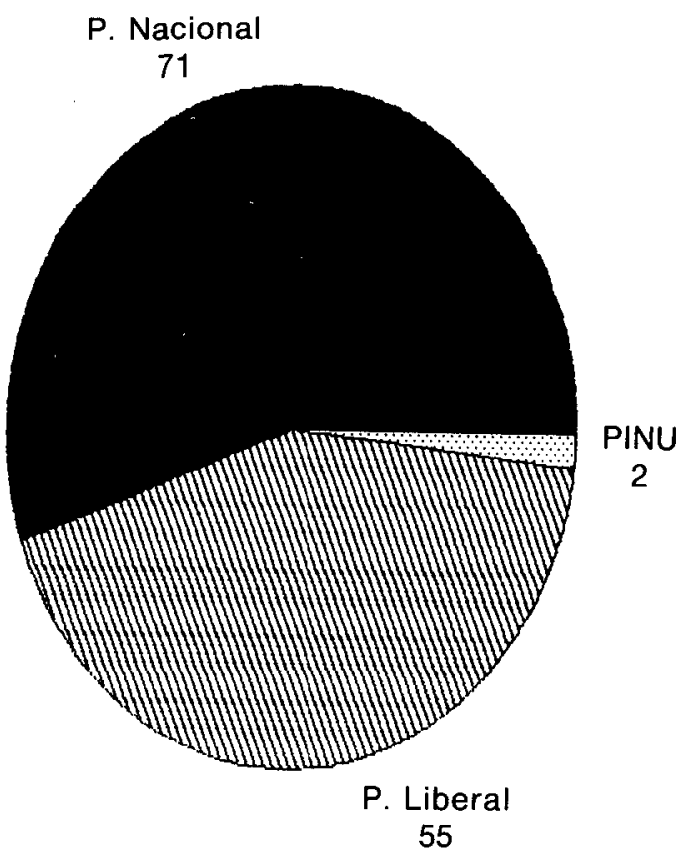


4. CUADROS COMPARATIVOS DE LAS ELECCIONES HABIDAS DURANTE EL PROCESO DE TRANSICION DEMOCRATICA

Partido Liberal

Partido Nacional

$\%$ OBTENIDO POR PARTIDOS

\begin{tabular}{|c|r|r|r|}
\hline \multicolumn{4}{|c|}{$\%$ OBTENIDO POR PARTIDOS } \\
\hline 1980 & 1981 & 1985 & 1989 \\
\hline 49,4 & 53,93 & 51 & 43,18 \\
42,4 & 41,62 & 45,5 & 50,97 \\
3,5 & 2,49 & 1,5 & 1,88 \\
- & 1,62 & 1,9 & 1,41 \\
\hline
\end{tabular}

Partido de Innovación Nacional

Partido Demócrata Cristiano

5. N. ${ }^{\circ}$ DE VOTOS POR PARTIDO 81-89

Partido Liberal

\begin{tabular}{|c|c|c|}
\hline 1981 & 1985 & 1989 \\
\hline 636.392 & 786.594 & 776.983 \\
491.089 & 701.506 & 17.168 \\
29.414 & 23.705 & 33.952 \\
19.163 & 30.173 & 25.453 \\
\hline
\end{tabular}




\section{CONCLUSIONES}

El triunfo electoral de Rafael Leonardo Calleja y del Partido Nacional, principal partido opositor desde que se iniciara la transición política en 1981, ha significado en nuestra opinión un considerable avance en la consolidación del sistema político democrático en Honduras, en cuanto que ha significado que un Presidente civil de una de las dos grandes formaciones políticas pueda traspasar el poder a otro de diferente organización política, hecho desconocido en el pais, y ello merced al resultado de las urnas.

En este aspecto destaca igualmente el acatamiento de los resultados electorales manifestados no sólo por las restantes fuerzas políticas sino por las denominadas «fuerzas vivas». Ejército e Iglesia, asi como por los gobiernos extranjeros, especialmente el de Estados Unidos.

Otro aspecto que parece consolidarse es el del bipartidismo, aunque de carácter atenuado, en virtud de que pueden existir corrientes o tendencias dentro de cada una de las dos formaciones políticas mayoritarias. Sin embargo, tanto en esta ocasión como en los anteriores comicios de 1985, se ha puesto de manifiesto que un partido que concurre a las elecciones excesivamente fragmentado pierde votos, tal caso le ocurrió al Partido Nacional en el 85 y al Liberal en la actualidad.

Cabe destacar la ausencia de incidentes importantes durante el proceso electoral, así como el funcionamiento de la "complicada" organización electoral, salvo la suspensión del voto domiciliario y el retraso por parte del Tribunal Nacional de Elecciones en dar a conocer los resultados electorales.

Quedaría, quizás, pendiente una posible reforma del texto constitucional y la Ley Electoral y de Organizaciones Políticas que reste "rigidez" a las condiciones de legibilidad por los candidatos a la Jefatura del Estado, así como al control que el aparato del Estado ejerce sobre la organización interna de los partidos políticos, y que parecen más residuos del pasado y propios de una Democracia en fase de consolidación que de un sistema político consolidado, por ello seria necesario indudablemente la aplicación de una política de consenso entre las dos grandes formaciones políticas. 